\title{
Estrogenic/Antiestrogenic Activities of Polycyclic Aromatic Hydrocarbons and Their Monohydroxylated Derivatives by Yeast Two-Hybrid Assay
}

\author{
Kazuichi Hayakawa, ${ }^{, a}$ Yu Onoda, ${ }^{a}$ Chihiro Tachikawa, ${ }^{a}$ Shinzo Hosoi, ${ }^{b}$ Morio Yoshita, ${ }^{a}$ \\ Sang Woon Chung, ${ }^{a}$ Ryoichi Kizu, ${ }^{c}$ Akira Toriba, ${ }^{a}$ Takayuki Kameda, ${ }^{a}$ and Ning Tang ${ }^{a}$ \\ ${ }^{a}$ Graduate School of Natural Science and Technology, Kanazawa University, Kakuma-machi, Kanazawa 920-1192, Japan, ${ }^{b}$ Kyushu \\ University of Health and Welfare, 1714-1 Yoshino-machi, Nobeoka 882-8508, Japan, and ${ }^{c}$ Faculty of Pharmaceutical Sciences, \\ Doshisha Women's College, Kodo, Tanabe, Kyoto 610-0395, Japan
}

(Received July 24, 2007; Accepted August 10, 2007; Published online August 10, 2007)

\begin{abstract}
Estrogenic/antiestrogenic activities of 14 polycyclic aromatic hydrocarbons (PAHs) and 63 monohydroxylated PAHs (OHPAHs) having 2 to 6 rings were evaluated by yeast two-hybrid assay expressing human estrogen receptor $\alpha$. Relative effective potencies of estrogenic and antiestrogenic activities were calculated as the inverse values of the relative concentration of the test compound that gave the same activities of $\mathrm{E}_{2}$ and 4-hydroxytamoxifen, respectively. PAHs did not show any estrogenic/antiestrogenic activity, but several OHPAHs having 3 to 5 rings showed activities. Especially, OHPAHs having 4 rings such as 3-, 4- and 10-hydroxybenz[a]anthracenes (3-, 4- and 10OHBaAs) and 2-hydroxychrysene (2-OHCh) showed strongly estrogenic activity. Several other OHPAHs having 4 rings such as 2- and 3-hydroxybenzo[c]phenanthrenes (2-, 3- OHBcPhs), 2-OHBaA and 3-OHCh showed strongly antiestrogenic activity. The length-to-breadth (L/B) ratios of the rectangular van der Walls planes surrounding the ring molecules of estrogenic OHPAHs were in the narrow range from 1.599 to 1.734 . The distances between the oxygen atom of the phenol group and farthest hydrogen atom $(\mathrm{O}-\mathrm{H}$ distance) of the estrogenic OHPAHs ranged from $10.825 \AA$ to $11.738 \AA$. The $\mathrm{L} / \mathrm{B}$ ratios and $\mathrm{O}-\mathrm{H}$ distances of antiestrogenic OHPAHs were in the wider ranges from 1.277 to 1.734 and from $8.47 \AA$ to $11.681 \AA$, respectively. The partial charges (atomic unit) of the phenol group of both estrogenic and antiestrogenic OHPAHs were in the range from -0.250 atmic unit (au) to -0.253 au. The similarity of these values to those of $E_{2}$ and diethylstilbestrol suggested that the compositions of estrogenic OHPAHs were similar to them and that the compositional conditions of estrogenic OHPAHs were much smaller than those of antiestrogenic OHPAHs. These results raise the possibility of predicting the estrogenic/antiestrogenic activities of OHPAHs from their structural characteristics, although using only the above three parameters might not be enough for accurate estimations.
\end{abstract}

Key words — hydroxypolycyclic aromatic hydrocarbon, estrogen receptor, estrogenic activity, antiestrogenic activity, structure-activity relationship

\section{INTRODUCTION}

Polycyclic aromatic hydrocarbons (PAHs) are ubiquitous environmental pollutants. They are formed through incomplete combustion of fossil fuel, wood and other organic materials including automobile exhaust, domestic heating and industrial processes. Humans and animals are exposed to PAHs from environmental (air, water), dietary

\footnotetext{
*To whom corresponding should be addressed: Graduate School of Natural Science and Technology, Kanazawa University, Kakuma-machi, Kanazawa 920-1192, Japan. Tel.: +8176-234-4413; Fax: +81-76-234-4456; E-mail: hayakawa@p. kanazawa-u.ac.jp
}

and occupational sources, and also from cigarette smoke. ${ }^{1)}$ Many PAHs are carcinogenic in human and laboratory animals ${ }^{2)}$ and the principal concern regarding exposure to PAHs is that they increase the risk of cancer.

In recent years there has been increasing interest in endocrine disruptors which may cause dysfunction of human and wildlife endocrine systems leading to cancers, reproductive system abnormalities and immune system deficiencies. ${ }^{3,4)}$ Several screening test methods have been developed to evaluate the endocrine-disrupting activities of chemicals. As for PAHs, antiestrogenic activity was observed in a yeast assay system ${ }^{5)}$ and estrogenic ac- 
tivity was found in MCF-7 cells. ${ }^{6)}$ Yeast two-hybrid assay system based on the ligand-dependent interaction of estrogen receptor (ER) and its co-activator has been developed as a simple and effective screening biological system. The estrogenic activities of 517 chemicals including several monohydroxylated derivatives of PAHs (OHPAHs) were evaluated by using this method. A common structure of the above estrogenic compounds was a phenol with a hydrophobic moiety at the para-position without a bulky group at the ortho-position. ${ }^{7)}$ This result suggested that the structural similarity of several $\mathrm{OH}$ PAHs to $17 \beta$-estradiol, which binds to human estrogen receptor (hER), might account for their estrogenic or antiestrogenic activities.

OHPAHs are formed from the corresponding PAHs in the presence of cytochrome P450 enzymes (CYPs) in human and animals ${ }^{8)}$ as well as chemically in the atmosphere, ${ }^{9}$ suggesting that the concentrations of OHPAHs may increase easily in the body. It is important to clarify whether these compounds have any biological effects. Several studies have been conducted to evaluate the estrogenic and antiestrogenic activities of OHPAHs such as hydroxybenzo[a]pyrene $(\mathrm{OHBaP})$. Both 1and 2 -OHBaPs bound strongly to ER in rat cytosol but 4-, 5-, 6- and 12-OHBaPs bound poorly. ${ }^{10)}$ Both 3- and 10-OHBaPs showed antagonistic activity to a mixture of $\mathrm{ER} \alpha$ and $\beta .^{6}$ ) Recently, we have tested twelve $\mathrm{OHBaP}$ isomers (1- through 12-OHBaPs) using the competition binding as- say to $\operatorname{ER} \alpha$ and $\beta$, and the gene expression assay of the yeast two-hybrid assay system, and found that 1-, 2-, 3- and 9-OHBaPs were estrogenic and 8-OHBaP was antiestrogenic. ${ }^{11)} \mathrm{We}$ also identified 2-hydroxyfluorene (2-OHFl), 2- and 3hydroxyphenanthrenes, 1-hydroxypyrene (1-OHPy) and $n$-propyl- $p$-hydroxybenzoate in cigarette smoke condensate as estrogenic compounds. ${ }^{12)}$ These results suggested that the activities of OHPAHs might depend strongly on their structures. However, little is known about the activities of the hydroxyl derivatives of other PAHs.

In this study, we examined both estrogenic and antiestrogenic activities of $14 \mathrm{PAHs}$ and $63 \mathrm{OH}-$ PAHs having two to six rings in the yeast twohybrid assay system and discuss how their structural characteristics might affect the expression of both estrogenic and antiestrogenic activities.

\section{MATERIALS AND METHODS}

Chemicals - Chemical structures of PAHs and OHPAHs tested in this report are shown in Fig. 1. Naphthalene (Np), fluorene (Fl), phenanthrene $(\mathrm{Ph})$ anthracene (Ant) and benzo[k]fluoranthene (BkFR) were purchased from Kanto Chemical (Tokyo, Japan). Fluoranthene (FR), benz $[a]$ anthracene $(\mathrm{BaA})$ and benzo[ghi]perylene (BgPe) were purchased from Nakalai (Kyoto, Japan). Benzo[e]fluoranthene (BeFR), benzo[j]fluoranthene

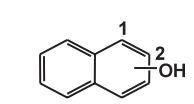

$\mathrm{Np}$ and OHNps

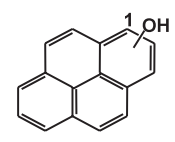

Py and OHPy

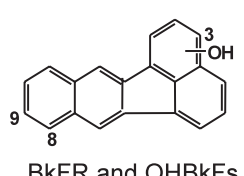

$\mathrm{BkFR}$ and $\mathrm{OHBkFs}$

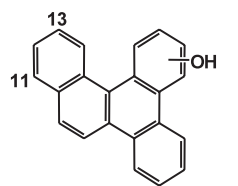

$\mathrm{BgCh}$ and $\mathrm{OHBgChs}$
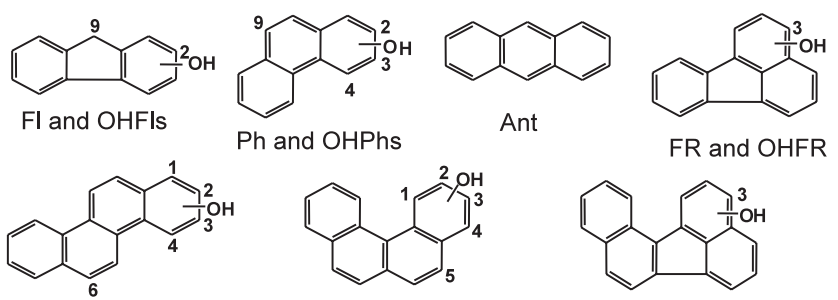

h and $\mathrm{OHChs}$
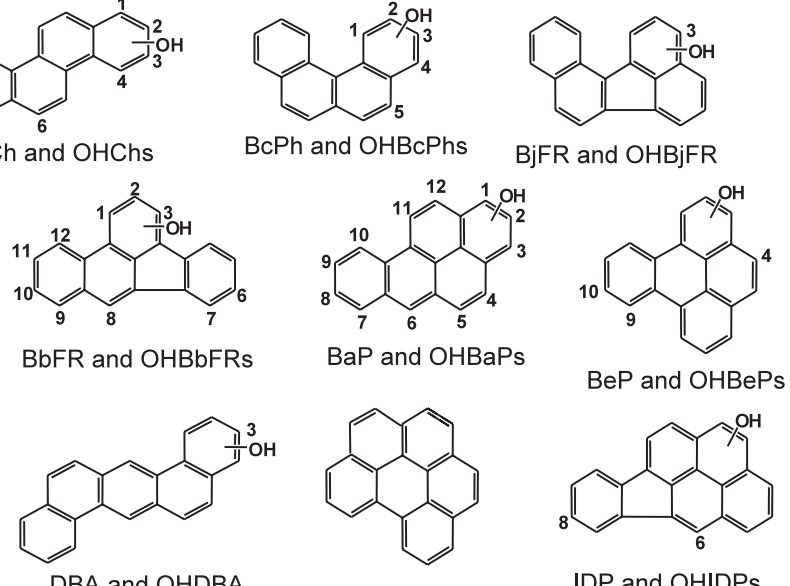

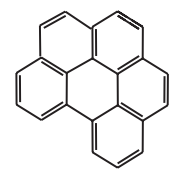

$\mathrm{BgPe}$

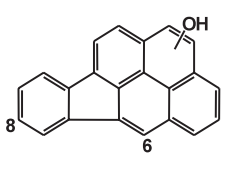

IDP and OHIDPs

Fig. 1. Chemical Structures of PAHs and OHPAHs Tested For abbreviations, see text. Numbers indicate the positions of hydroxyl groups. 
(BjFR), 1- and 2-hydroxynaphthalenes (1- and 2OHNps) and $17 \beta$-estradiol $\left(\mathrm{E}_{2}\right)$ were purchased from Wako Pure Chemicals (Osaka, Japan). $\left[2,4,6,7-{ }^{3} \mathrm{H}(\mathrm{N})\right]-\mathrm{E}_{2} \quad(72 \mathrm{Ci} / \mathrm{mmol})$ was purchased from Dai-Ichi Pure Chemicals (Tokyo, Japan). Pyrene (Py), chrysene (Ch), benzo $[a]$ pyrene $(\mathrm{BaP})$, benzo $[c]$ phenanthrene $(\mathrm{BcPh}), 2-$ and 9OHFls and 1-OHPy were purchased from Aldrich (Milwaukee, WI, U.S.A.). 4-Hydroxytamoxifen and benzo[e]pyrene (BeP) were from Sigma (St. Louis, MO, U.S.A.). Benzo[g]chrysene (BgCh), dibenz $[a, h]$ anthracene (DBA), 2-, 3-, 4- and 9-hydroxyphenanthrenes (2-, 3-, 4- and 9-OHPhs) were from Chiron AS (Trondheim, Norway). Indeno[1,2,3-cd]pyrene (IDP), 3hydroxyfluoranthene (3-OHFR), 1-, 2-, 3-, 4-, 5-, 9-, 10- and 11-hydroxybenz[ $a]$ anthracenes (1-, 2-, 3-, 4-, 5-, 9-, 10- and 11-OHBaAs), 1-, 2-, 3-, 4- and 6-hydroxychrysenes (1-, 2-, 3-, 4- and 6-OHChs), 11- and 13-hydroxybenzo[ $g]$ chrysenes (11- and 13-OHBgChs), 1-, 2-, 3-, 6-, 7-, 8-, 9-, $10-, 11-$ and 12-hydroxybenzo[ $b]$ fluoranthenes (1-, 2-, 3-, 6-, 7-, 8-, 9-, 10-, 11- and 12-OHBbFRs), 3-hydroxybenzo[j]fluoranthene (3-OHBjFR), 3-, 8- and 9-hydroxybenzo[k]fluoranthenes (3-, 8- and 9-OHBkFRs), 1-, 2-, 3-, 4- and 5- hydroxybenzo $[c]$ phenanthrenes $(1-,, 2-, \quad 3-, \quad 4-$ and 5-OHBcPhs), 1-, 2-, 3-, 4-, 5-, 6-, 7-, 8-, 9-, 10-, 11- and 12-OHBaPs, 4-, 9- and 10hydroxybenzo[ $e]$ pyrenes (4-, 9- and 10-OHBePs), 3-hydroxydibenz $[a, h]$ anthracene (3-OHDBA) and 6- and 8-hydroxyindeno[1,2,3-cd]pyrenes (6- and 8-OHIDPs) were purchased from NCI Chemical Carcinogen Repository (Kansas City, MO, U.S.A.). Test compounds were dissolved in ethanol and stored at $-20^{\circ} \mathrm{C}$ until use. All other chemicals were of the highest quality available from commercial sources.

\section{Assay of Estrogenic and Antiestrogenic Activ-} ities — Yeast cells expressing hER $\alpha$ or $\beta$ were prepared according to the previous report. ${ }^{12)}$ Estrogenic and antiestrogenic activities of PAHs and $\mathrm{OH}-$ PAHs were evaluated by the yeast two-hybrid assay method using the above yeast cells as described. ${ }^{11)}$ To examine the agonistic activity of PAHs and OHPAHs, the yeast cells were grown overnight at $27^{\circ} \mathrm{C}$ with shaking in synthetic defined medium free from tryptophan and leucine, and treated with each test compound in the concentration range from $1 \times 10^{-9} \mathrm{M}$ to $1 \times 10^{-6} \mathrm{M}$ at $27^{\circ} \mathrm{C}$ for $4 \mathrm{hr}$. After the incubation, the treated cells were collected and enzymatically digested with $1 \mathrm{mg} / \mathrm{ml}$ Zymolyase $20 \mathrm{~T}$ at $37^{\circ} \mathrm{C}$ for $20 \mathrm{~min}$. 2-Nitrophenyl- $\beta$-D-galactoside (ONPG) was added to the lysate to a final concentration of $4 \mathrm{mg} / \mathrm{ml}$. After incubation at $27^{\circ} \mathrm{C}$ for $20 \mathrm{~min}$, the reaction was stopped by the addition of $1 \mathrm{M} \mathrm{Na}_{2} \mathrm{CO}_{3}$. The yeast debris was removed by centrifugation and $\beta$-galactosidase activity was assayed by measuring the absorbance of supernatant at $415 \mathrm{~nm}$. Three independent experiments were run, and the mean values of the three were shown in this report. Relative effective potency of estrogenic activity $\left(\mathrm{REP}_{\mathrm{E}}\right)$ was calculated as the inverse value of the relative concentration of the test compound that gave the same activity of $E_{2}$. Relative effective potency of antiestrogenic activity $\left(\mathrm{REP}_{\mathrm{AE}}\right)$ was calculated as the inverse value of the relative concentration of the test compound that gave the same activity of 4-hydroxytamoxifen in the presence of $1 \mathrm{nM} \mathrm{E}_{2}$.

Competition Binding Assay — Competition between the test compounds and $\mathrm{E}_{2}$ was measured as described previously. ${ }^{13)}$ A crude extract prepared from Sf21 insect cells infected with hER $\alpha$ or $\beta$ recombinant virus, kindly supplied by Professor T. Nishihara, Osaka University, was used for competition binding assay. Various concentrations of a test compound and $1.25 \mathrm{pmol}$ of $\left[2,4,6,7-{ }^{3} \mathrm{H}(\mathrm{N})\right]-\mathrm{E}_{2}$ were incubated in $250 \mu \mathrm{l}$ of reaction mixture of TKE (20 mM Tris- $\mathrm{HCl}$ at $\mathrm{pH} 7.4,20 \mathrm{mM} \mathrm{KCl}$ and $1 \mathrm{mM}$ EDTA) containing $5 \mu \mathrm{hER} \alpha$ or $\beta$ at $0^{\circ} \mathrm{C}$ for $16 \mathrm{hr}$. Free and bound ligands were separated by addition of an equal volume of dextran-coated charcoal. Samples were periodically mixed on ice for $5 \mathrm{~min}$ and centrifuged at $15000 \mathrm{rpm}$ for $1 \mathrm{~min}$. Aliquots $(300 \mu \mathrm{l})$ of the supernatant were used for scintillation counting.

Calculation of Physical Parameters — In order to examine the relationship between structure and activity, several physical parameters of PAHs and OHPAHs were used. The length-to-breadth (L/B) ratios $^{14)}$ of the rectangular van der Walls plane surrounding each $\mathrm{PAH}$ molecule were obtained from the Polycyclic Aromatic Hydrocarbon Structure Index. ${ }^{15)}$ The $\mathrm{O}-\mathrm{H}$ distance, the distance between the oxygen atom of the phenol group and the hydrogen atom located farthest from the phenol group, and the partial charge (atomic charge, au) of the phenol group were calculated with a molecular modeling program (CAChe Worksystem ver.4.1.1 for Apple Macintosh, Fujitsu Co. Ltd., Chiba, Japan).

\section{Determination of OHPAHs in Yeast Cells}

Yeast cells incubated with test compound were enzymatically digested according to the procedures 
described above (Assay of estrogenic and antiestrogenic activities). The digested yeast cells was mixed with acetonitrile and centrifuged. The upper (acetonitrile) phase was collected, filtered with a membrane and an aliquot of the filtrate was injected into the HPLC with a fluorescence detector. OHPAHs were quantified by using deuterated OHPAHs as internal standards according to our previous report, ${ }^{16)}$ with some modifications of mobile phases, detection wavelengths and time program.

\section{RESULTS}

\section{Estrogenic Activity}

None of the 14 PAHs (Np, Fl, Ph, Ant, FR,
Py, BaA, Ch, BbFR, BkFR, BaP, DBA, BgPe and IDP) showed estrogenic activity at concentrations between $1 \times 10^{-6} \mathrm{M}$ and $1 \times 10^{-9} \mathrm{M}$. A significant increase of $\beta$-galactosidase activity $\left(\operatorname{REP}_{\mathrm{E}}>1 \times 10^{-3}\right)$ was observed for 3-, 4- and 10-OHBaAs and 2$\mathrm{OHCh}$. These were all 4-ring OHPAHs. Among them, 4-OHBaA exhibited the strongest estrogenic activity $\left(\mathrm{REP}_{\mathrm{E}}=7.5 \times 10^{-3}\right)$. 2-OHFl, 2-OHPh (3ring), 3-OHFR, 1-OHPy, 1-OHCh, 12-OHBbFR, 3OHBkFR (4-ring), and 4-OHBeP (5-ring) were also active $\left(1 \times 10^{-3}>\operatorname{REP}_{\mathrm{E}} \geq 1 \times 10^{-4}\right)$. The estrogenic activities of the other OHPAHs were much weaker or undetectable (Table 1).

\section{Antiestrogenic Activity}

None of the 14 PAHs as tested for estrogenic

Table 1. Estrogenic and Antiestrogenic Activities of OHPAHs by Yeast Two-Hybrid Assay

\begin{tabular}{|c|c|c|c|c|c|c|c|}
\hline $\begin{array}{l}\text { No. of } \\
\text { rings }\end{array}$ & $\begin{array}{l}\text { Abbre- } \\
\text { viation }\end{array}$ & $\begin{array}{c}\mathrm{REP}_{\mathrm{E}}^{a)} \\
\times 10^{-4} \\
\end{array}$ & $\begin{array}{c}\mathrm{REP}_{\mathrm{AE}}^{b)} \\
\times 10^{-2}\end{array}$ & $\begin{array}{c}\text { No. of } \\
\text { rings }\end{array}$ & $\begin{array}{l}\text { Abbre- } \\
\text { viation }\end{array}$ & $\begin{array}{c}\mathrm{REP}_{\mathrm{E}}^{a)} \\
\times 10^{-4} \\
\end{array}$ & $\begin{array}{c}\mathrm{REP}_{\mathrm{AE}}^{b)} \\
\times 10^{-2}\end{array}$ \\
\hline \multirow[t]{2}{*}{2} & $1-\mathrm{OHNp}$ & $<1$ & $<1$ & \multirow[t]{29}{*}{5} & 6-OHBbFR & $<1$ & 3.6 \\
\hline & 2-OHNp & $<1$ & $<1$ & & 7-OHBbFR & $<1$ & $<1$ \\
\hline \multirow[t]{6}{*}{3} & $2-\mathrm{OHFl}$ & 5.6 & $<1$ & & 8-OHBbFR & $<1$ & $<1$ \\
\hline & 9-OHFl & $<1$ & $<1$ & & 9-OHBbFR & $<1$ & $<1$ \\
\hline & 2-OHPh & 7.5 & $<1$ & & 10-OHBbFR & $<1$ & 7.6 \\
\hline & 3-OHPh & $<1$ & $<1$ & & 11-OHBbFR & $<1$ & $<1$ \\
\hline & 4-OHPh & $<1$ & $<1$ & & 12-OHBbFR & 1 & $<1$ \\
\hline & 9-OHPh & $<1$ & $<1$ & & 3-OHBjFR & $<1$ & $<1$ \\
\hline \multirow[t]{20}{*}{4} & 3-OHFR & 4.2 & $<1$ & & 3-OHBkFR & 1.3 & $<1$ \\
\hline & 1-OHРy & 2.4 & $<1$ & & 8-OHBkFR & $<1$ & $<1$ \\
\hline & 1-OHBaA & $<1$ & $<1$ & & 9-OHBkFR & $<1$ & 21 \\
\hline & 2-OHBaA & $<1$ & 42 & & 1-OHBaP & $<1$ & $<1$ \\
\hline & 3-OHBaA & 42 & $<1$ & & 2-OHBaP & $<1$ & $<1$ \\
\hline & 4-OHBaA & 75 & $<1$ & & 3-OHBaP & $<1$ & $<1$ \\
\hline & 5-OHBaA & $<1$ & $<1$ & & 4-OHBaP & $<1$ & $<1$ \\
\hline & 9-OHBaA & $<1$ & 34 & & 5-OHBaP & $<1$ & $<1$ \\
\hline & $10-\mathrm{OHBaA}$ & 32 & $<1$ & & 6-OHBaP & $<1$ & $<1$ \\
\hline & 11-OHBaA & $<1$ & $<1$ & & 7-OHBaP & $<1$ & $<1$ \\
\hline & $1-\mathrm{OHBcPh}$ & $<1$ & $<1$ & & 8-OHBaP & $<1$ & 43 \\
\hline & 2-OHBcPh & $<1$ & 69 & & 9-OHBaP & $<1$ & $<1$ \\
\hline & $3-\mathrm{OHBcPh}$ & $<1$ & 190 & & 10-OHBaP & $<1$ & $<1$ \\
\hline & $4-\mathrm{OHBcPh}$ & $<1$ & 13 & & 11-OHBaP & $<1$ & $<1$ \\
\hline & $5-\mathrm{OHBcPh}$ & $<1$ & 1.2 & & 12-OHBaP & $<1$ & $<1$ \\
\hline & 1-OHCh & 4.2 & $<1$ & & 4-OHBeP & 4.2 & $<1$ \\
\hline & 2-OHCh & 42 & $<1$ & & 9-OHBeP & $<1$ & $<1$ \\
\hline & 3-OHCh & $<1$ & 40 & & 10-OHBeP & $<1$ & $<1$ \\
\hline & 4-OHCh & $<1$ & $<1$ & & 11-OHBgCh & $<1$ & 29 \\
\hline & 6-OHCh & $<1$ & 30 & & 13-OHBgCh & $<1$ & 22 \\
\hline \multirow[t]{3}{*}{5} & 1-OHBbFR & $<1$ & $<1$ & & 3-OHDBA & $<1$ & $<1$ \\
\hline & 2-OHBbFR & $<1$ & $<1$ & \multirow[t]{2}{*}{6} & 6-OHIDP & $<1$ & $<1$ \\
\hline & 3-OHBbFR & $<1$ & $<1$ & & 8-OHIDP & $<1$ & $<1$ \\
\hline
\end{tabular}

a) Estrogenic activity of each test compound was assayed in the concentration range from $1 \times 10^{-6} \mathrm{M}$ to $1 \times 10^{-9} \mathrm{M}$. $\mathrm{REP}_{\mathrm{E}}$ was calculated from the value of $\mathrm{E}_{2}$ as a positive control. b) Antiestrogenic activity of each test compound was assayed in the concentration range from $1 \times 10^{-6} \mathrm{M}$ to $1 \times 10^{-9} \mathrm{M}$. $\mathrm{REP}_{\mathrm{AE}}$ was calculated from the value of 4hydroxytamoxifen as a positive control. 
assay showed antiestrogenic activity at concentrations between $1 \times 10^{-6} \mathrm{M}$ and $1 \times 10^{-9} \mathrm{M}$. On the other hand, several OHPAHs showed antiestrogenic activity. A significant decrease of $\beta$ galactosidase activity $\left(\mathrm{REP}_{\mathrm{AE}}>1 \times 10^{-1}\right)$ was observed for 2- and 9-OHBaAs, 2-, 3- and 4OHBcPhs, 3- and 6-OHChs (4-ring), 9-OHBkFR, 8-OHBaP, 11- and 13-OHBgChs (5-ring). Among them, 3-OHBcPh exhibited the strongest antiestrogenic activity $\left(\mathrm{REP}_{\mathrm{AE}}=1.9\right)$. 5-OHBcPh, 6- and 10-OHBbFRs showed weak activity $\left(1 \times 10^{-1} \geq\right.$

Table 2. Binding Affinity of PAHs and OHPAHs to hER

\begin{tabular}{|c|c|c|}
\hline No. of rings & Abbrviation & $\begin{array}{c}\text { Relative binding } \\
\left.\text { affinity }^{a}\right)\end{array}$ \\
\hline \multirow[t]{2}{*}{3} & $2-\mathrm{OHFl}$ & 0.128 \\
\hline & 2-OHPh & 0.232 \\
\hline \multirow[t]{25}{*}{4} & Frt & 0.005 \\
\hline & 3-OHFR & 0.207 \\
\hline & Py & 0.004 \\
\hline & 1-OHPy & 0.110 \\
\hline & $\mathrm{BaA}$ & 0.005 \\
\hline & 1-OHBaA & 0.047 \\
\hline & 2-OHBaA & 0.137 \\
\hline & 3-OHBaA & 0.228 \\
\hline & 4-OHBaA & 0.294 \\
\hline & 5-OHBaA & 0.058 \\
\hline & 9-OHBaA & 0.410 \\
\hline & 10-OHBaA & 0.295 \\
\hline & 11-OHBaA & 0.027 \\
\hline & $\mathrm{BcPh}$ & 0.002 \\
\hline & 1-OHBcPh & 0.001 \\
\hline & 2-OHBcPh & 0.185 \\
\hline & 3-OHBcPh & 0.345 \\
\hline & 4-OHBcPh & 0.210 \\
\hline & 5-OHBcPh & 0.044 \\
\hline & $\mathrm{Ch}$ & 0.003 \\
\hline & 1-OHCh & 0.126 \\
\hline & 2-OHCh & 0.406 \\
\hline & 3-OHCh & 0.138 \\
\hline & 4-OHCh & 0.012 \\
\hline & 6-OHCh & 0.090 \\
\hline \multirow[t]{9}{*}{5} & 10-OHBbFR & 0.115 \\
\hline & 3-OHBkFR & 0.150 \\
\hline & 9-OHBkFR & 0.205 \\
\hline & 1-OHBaP & 0.187 \\
\hline & 3-OHBaP & 0.394 \\
\hline & 8-OHBaP & 0.376 \\
\hline & 4-OHBeP & 0.117 \\
\hline & 11-OHBgCh & 0.197 \\
\hline & 13-OHBgCh & 0.135 \\
\hline
\end{tabular}

a) hER $\alpha$ was used in this assay. $b$ ) Relative binding affinity of each test compound $\left(1 \times 10^{-5} \mathrm{M}\right)$ was calculated from binding affinity of $\mathrm{E}_{2}\left(1 \times 10^{-7} \mathrm{M}\right)$ as a competitor.
$\operatorname{REP}_{\mathrm{AE}} \geq 1 \times 10^{-2}$ ). The relative antiestrogenic activities of the other OHPAHs were much weaker or undetectable (Table 1).

\section{Competition Binding Assay}

No component from uninfected Sf 2 cells (i.e. cells that did not express $\operatorname{hER} \alpha$ and $\beta$ ) bound to hER non-specifically. Thus, any decrease of bound $\left[2,4,6,7-{ }^{3} \mathrm{H}(\mathrm{N})\right]-\mathrm{E}_{2}$ in the presence of one of the test compounds was attributed to competitive binding to hER. Four- and 5-ring PAHs did not bind to either $\mathrm{hER} \alpha$ or $\beta$ (relative binding affinity $\leq 5 \times 10^{-3}$ ), while each of the corresponding OHPAHs except for $1-\mathrm{OHBcPh}$ bound to hER (relative binding affinity $>1 \times 10^{-2}$ ). 2-OHPh, 3-OHFR, 3-, 4-, 9- and 10OHBaAs, 3- and 4-OHBcPhs, 2-OHCh, 10-BkFR, 3- and 8-OHBaPs showed strong binding affinity to $\operatorname{hER} \alpha$ (relative binding affinity $>2 \times 10^{-1}$ ). Among them, 9-OHBaA and 2-OHCh showed the strongest binding affinities (relative binding affinity $\approx 4.1 \times 10^{-1}$ ) (Table 2). In general, these OHPAHs bound more strongly to hER $\beta$ than to $\mathrm{hER} \alpha$, but the difference was small. So, the relative binding affinities to only hER $\alpha$ are listed in Table 2.

\section{DISCUSSION}

One of the way in which a compound can have estrogenic/antiestrogenic activity is to have an affinity for hER. Several 3-ring PAHs, such as Ant and $\mathrm{Ph}$, have antiestrogenic activity. ${ }^{17)}$ However, in our present study, their activities were much weaker than the activity of 4-OHT. Moreover, 4-ring PAHs such as FR, $\mathrm{Py}, \mathrm{BaA}, \mathrm{BcPh}$ and $\mathrm{Ch}$ did not bind to hER (Table 2) and did not show any activities. Thirty-one OHPAHs having 3 to 5 rings bound to hER except for 1-OHBcPh, whose binding affinity was as low as the affinity of $\mathrm{BcPh}$ (Table 2). Among the OHPAHs tested, only a few compounds exhibited estrogenic or antiestrogenic activity in the yeast-two hybrid assay system (Table 1). In order to check the adsorption of OHPAHs into yeast cells, yeast cells were incubated with 1-, 2- and 4$\mathrm{OHBaAs}$ as inactive, estrogenic and antiestrogenic compounds according to their $\mathrm{REP}_{\mathrm{E}}$ and $\mathrm{REP}_{\mathrm{AE}}$ values, respectively. When the cells were digested and the solution was extracted with acetonitrile, 38$42 \%$ of the three OHBaAs added were recovered from the yeast cells. These results mean that $\mathrm{OH}$ PAHs passed though the cell membrane and bound to hER in the nucleus. BaA was recovered from 
the yeast cells incubated with $\mathrm{BaA}$, suggesting that $\mathrm{PAH}$, that have a larger $\mathrm{P}_{\mathrm{o} / \mathrm{w}}$ value than their corresponding OHPAH, also passed through the cell membrane. However, PAHs could not bind to the active cite of hER because of the absence of a phenol group. This might be the reason for the large difference between PAHs and OHPAHs in estrogenic activities. The data in Table 1 suggest that the phenol group is necessary for OHPAHs to exhibit both estrogenic and antiestrogenic activities. However, we have recently found that several quinoid derivatives of PAHs showed strong antiestrogenic activities, suggesting hydroxyl group is not necessary for exhibiting antiestrogenic activity.

The binding affinities of the OHPAHs to hER $\alpha$ were correlated with their estrogenic activities (Fig. $\left.2 \mathrm{~A} ; \mathrm{R}^{2}=0.6146\right)$ and weakly correlated with their antiestrogenic activities (Fig. $2 \mathrm{~B} ; \mathrm{R}^{2}=$ 0.4115). However, 2-OHCh and 9-OHBaP, which had the strongest binding affinities to $\operatorname{hER} \alpha$, were not the strongest estrogenic and antiestrogenic $\mathrm{OH}-$ PAHs, respectively. Thus, OHPAHs, which had the strongest affinity, did not always exhibit the strongest estrogenic or antiestrogenic activity, suggesting that the binding affinity to hER was not the only factor to control the estrogenic or antiestrogenic activity.
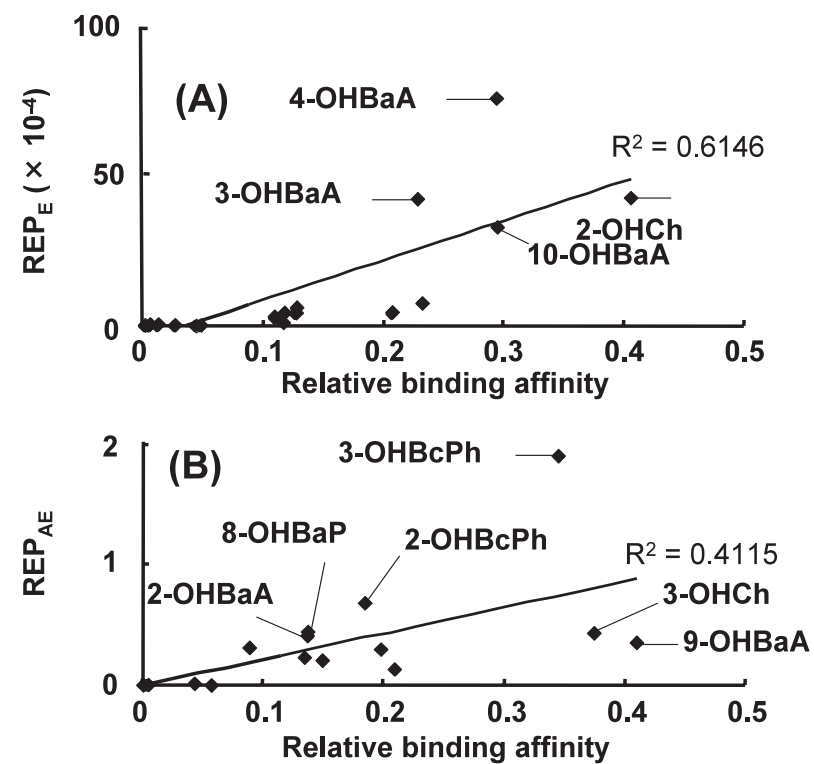

Fig. 2. Relationships between Binding Affinity to hER $\alpha$ and (A) $\mathrm{REP}_{\mathrm{E}}$ and (B) $\mathrm{REP}_{\mathrm{AE}}$ of OHPAHs by Yeast TwoHybrid Assay

Relative binding affinity was calculated from binding affinity of $E_{2}$ as a competitor. $\mathrm{REP}_{\mathrm{E}}$ and $\mathrm{REP}_{\mathrm{AE}}$ were calculated from the values of $\mathrm{E}_{2}$ and 4-OHT.
Strong estrogenic activity was mainly observed in 4-ring OHPAHs (Fig. 3A). Several 3-ring OHPAHs such as 2-OHFl, 2- and 3-OHFls were identified in cigarette smoke condensate as estrogenic compounds. ${ }^{12)}$ Among these 3-ring PAHs, 2-OHPh gave the largest $\operatorname{REP}_{\mathrm{E}}\left(=7.5 \times 10^{-4}\right)$ followed by 2 $\mathrm{OHFl}$, but the value was 10 times smaller than that of 4-OHBaA which showed the strongest estrogenic activity. Strongly antiestrogenic activity was also observed in several OHPAHs having 4 and 5 rings (Fig. 3B). However, many other 4- and 5-ring OHPAHs were inactive (Table 1). Thus, the numbers of rings of OHPAH was one of factors controlling estrogenic or antiestrogenic activity.

It has been reported that the phenol group $(\mathrm{OH}-$ 3) of $E_{2}$ makes hydrogen bonds with Glu353 and Arg394 of hER and $\mathrm{H}_{2} \mathrm{O}$ and that the alcohol group (OH-17) of $\mathrm{E}_{2}$ has an affinity for the nitrogen atom of His524 of hER. Among these hydrogen bonds, the distance between Glu353 and the phenol group was the shortest $(2.37 \AA)$, which suggests that this bond is the strongest. On the other hand, van der Walls interaction takes place between the benzene ring of $E_{2}$ and the benzene ring of Phe 404 of the binding site of hER. ${ }^{18,19)}$ These reports suggest whether 4-ring OHPAHs interact with the binding site of hER depends on the conformation of the benzene ring and the position of the phenol group.

Estrogenic compounds usually consist of phenols with hydrophobic moiety at the para-position
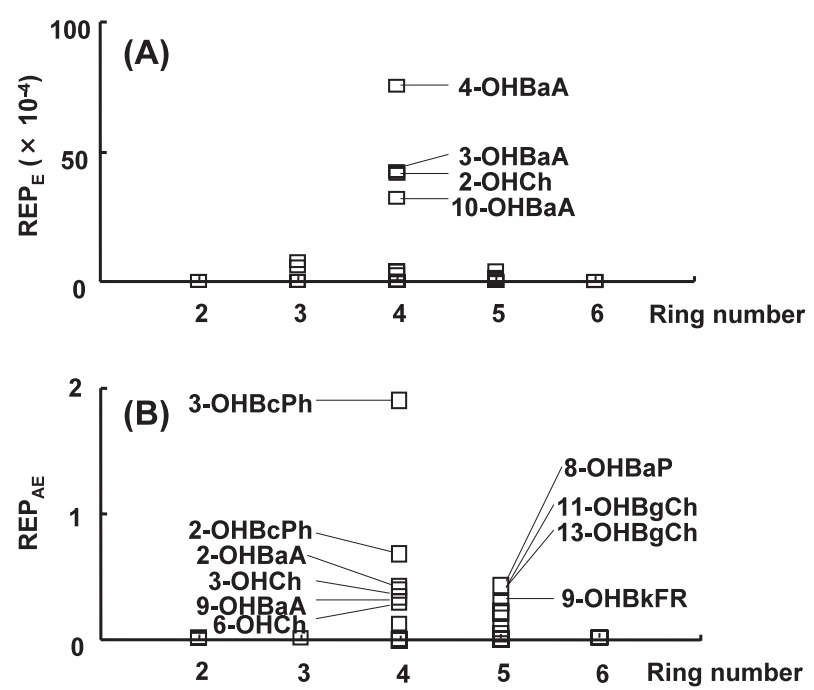

Fig. 3. Relationship between Number of Rings of OHPAHs and (A) $\mathrm{REP}_{\mathrm{E}}$ and (B) Calculated from The Values of $\mathrm{E}_{2}$ and 4-OHT OHT. 
without a bulky group at the ortho-position. ${ }^{7)}$ However, 4-OHBaA, which has a bulky group (Ant) at the ortho-position of phenol, was strongly estrogenic $\left(\operatorname{REP}_{\mathrm{E}}=7.5 \times 10^{-3}\right.$; Table 1$)$. Our results suggest that bulkiness only at the ortho-position might not be enough to suppress estrogenic activity. As shown in Fig. 4, the L/B ratio and the O-H distance might also have an affect on the activity. The strongly estrogenic 4-ring OHPAHs [3-, 4- and 10OHBaAs and 2-OHCh $\left.\left(\operatorname{REP}_{\mathrm{E}} \geq 3.2 \times 10^{-3}\right)\right]$, had $\mathrm{L} / \mathrm{B}$ ratios in the range from 1.599 to 1.734 and $\mathrm{O}-\mathrm{H}$ distances in the range from $10.825 \AA$ to $11.738 \AA$. The other 4-ring OHPAHs that were outside this area did not have such strong estrogenic activity.

Compounds having a strong affinity to hER, such as $E_{2}$ and diethylstilbestrol (DES), have two hydroxyl groups with the appropriate $\mathrm{O}-\mathrm{O}$ distance. ${ }^{18)}$ The $\mathrm{L} / \mathrm{B}$ ratios of $\mathrm{E}_{2}$ and DES were 1.545 and 1.515 , respectively. The $\mathrm{O}-\mathrm{O}$ distances of $\mathrm{E}_{2}$ and DES were $10.97 \AA$ and $12.03 \AA$, respectively. These $\mathrm{L} / \mathrm{B}$ ratios and $\mathrm{O}-\mathrm{O}$ distances were close to the values of $\mathrm{L} / \mathrm{B}$ ratios and $\mathrm{O}-\mathrm{H}$ distances of the above four strongly estrogenic OHPAHs (Fig. 5).

On the other hand, the strongly antiestrogenic 4and 5-ring OHPAHs [2- and 9-OHBaAs, 2- and 3OHBcPhs, 3- and 6-OHChs, 9-OHBkFR, 8-OHBaP and 11- and 13-OHBgChs $\left.\left(\operatorname{REP}_{\mathrm{AE}} \geq 0.21\right)\right]$, had $\mathrm{L} / \mathrm{B}$ ratios of 1.277 to 1.734 and $\mathrm{O}-\mathrm{H}$ distances of $8.47 \AA$ to $11.681 \AA$. The area of the L/B ratio and $\mathrm{OH}$ distance of strongly antiestrogenic $\mathrm{OH}-$ PAHs was much larger than that of strongly estrogenic OHPAHs described above. All of these antiestrogenic compounds except 9-OHBaA were outside the area of strong estrogenic compounds as

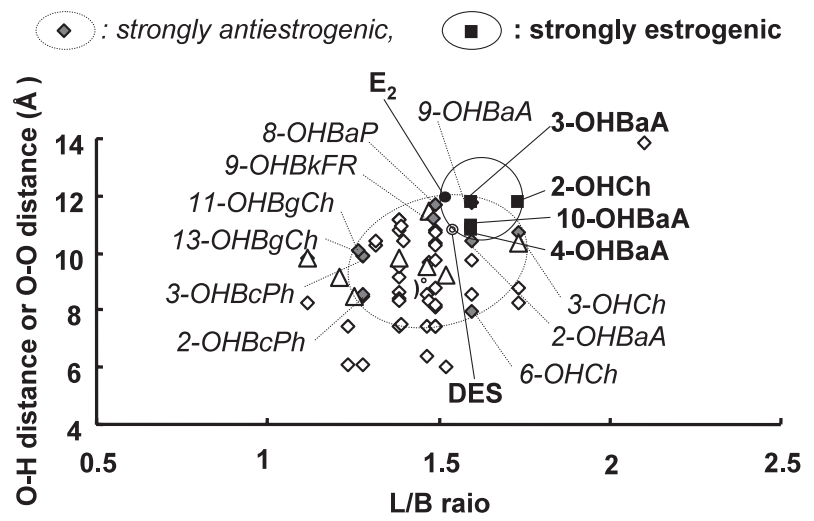

Fig. 4. Relationships between L/B Ratio and O-H Distance Values of Estrogenic and Antiestrogenic OHPAHs

$\mathrm{hER} \alpha$ was used in the assay. Symbols: $\mathbf{\square}$; $\operatorname{REP}_{\mathrm{E}} \geq 0.001, \diamond$; $\operatorname{REP}_{\mathrm{AE}}>0.1, \odot$; $\mathrm{E}_{2}, \bullet$; DES. In the cases of $\mathrm{E}_{2}$ and DES, O-O distance was used instead of $\mathrm{O}-\mathrm{H}$ distance. described above. Although it is unclear why 9$\mathrm{OHBaA}$ was an exception, this result suggests that the antagonistic OHPAHs can exhibit activity even when they bind to sites other than the active site of hER.

Finally, we examined the partial charge of the phenol group of OHPAHs that is peculiar to compounds elected by Austin Model 1 (AM1), since AM1 has often been used to quantify the structureactivity relationship as according to the semiempirical molecular orbital theory. ${ }^{18,20,21)}$ The partial charge was related to estrogenic activity (Fig. 5A) as well as antiestrogenic activity (Fig. 5B). The partial charges of strongly estrogenic OHPAHs $\left(\mathrm{REP}_{\mathrm{E}} \geq 7.5 \times 10^{-4}\right)$ ranged from -0.249 atomic unit (au) to -0.253 au for both agonistic and antagonistic effects. This value was very close to the values of phenol groups of $E_{2}$ (partial charge $=-0.253 \mathrm{au}$ ) and DES (partial charge $=-0.252 \mathrm{au}$ ), but not so close to that of the alcohol group of $E_{2}$ (partial charge $=-0.318 \mathrm{au}$ ). The author also calculated other physical parameters such as ionization potential, dipole moment, dielectric energy and log $\mathrm{P}$ for all OHPAHs tested. However, there was not any relationship between these parameters and estrogenic/antiestrogenic activities.

It is interesting that 1- and 11-OHBaAs, whose phenol groups were on the Bay-region, did not
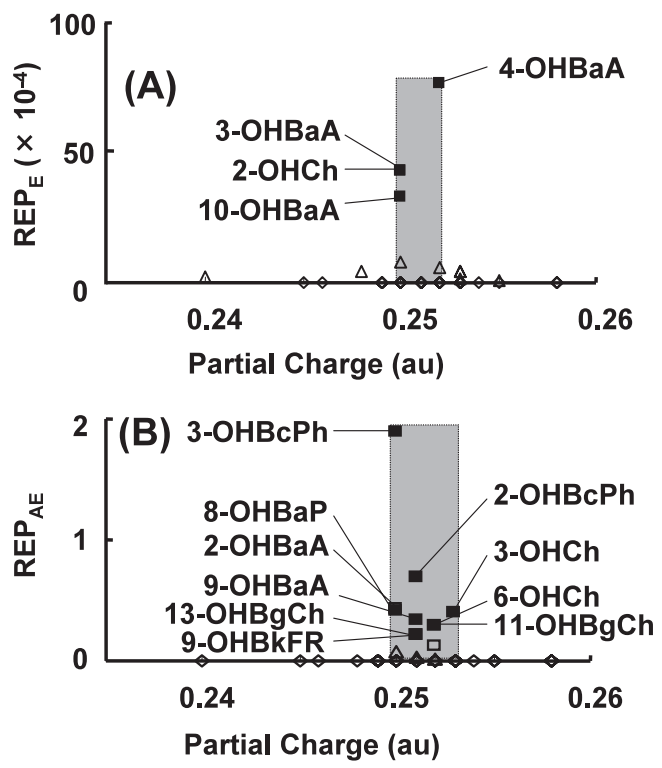

Fig. 5. Relationship between Partial Charge and $(A) R_{E P}$ and (B) $\mathrm{REP}_{\mathrm{AE}}$

$\mathrm{hER} \alpha$ was used in the assay. Symbols and relative activities are the same as in Fig. 3. $\mathrm{REP}_{\mathrm{E}}$ and $\mathrm{REP}_{\mathrm{AE}}$ were calculated from the values of $\mathrm{E}_{2}$ and 4-OHT. Unit of partial charge, atomic unit. 
6

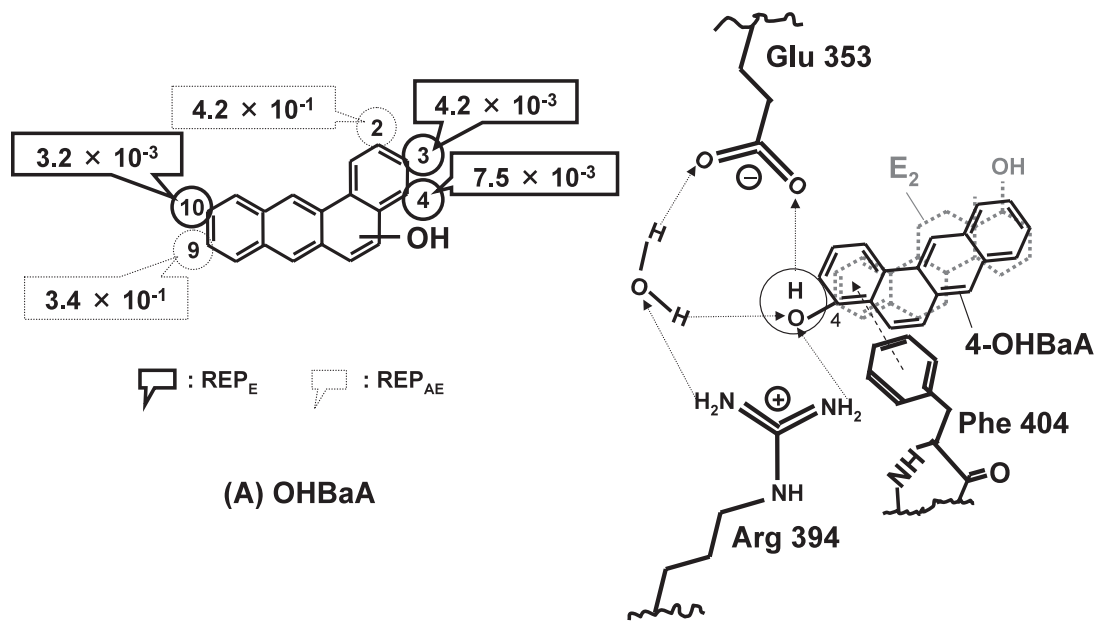

(B) A possible binding of 4-OHBaA to hER

Fig. 6. Structures of (A) OHBaAs and (B) A Possible Binding of 4-OHBaP to hER Dotted line in Fig. 5B means $\mathrm{E}_{2}$

show any activity and that 5-OHBaA, whose phenol group was on the K-region, did not. However, 3-, 4- and 10-OHBaAs showed strong estrogenic activity, while 2- and 9-OHBaAs showed strong antiestrogenic activity (Fig. 6A). All these active phenol groups were on the outside of the end rings of OHBaAs and the phenol groups of strongly antiestrogenic OHBaAs were next to the sites of the phenol groups of the above strongly estrogenic. As described above, the $\mathrm{L} / \mathrm{B}$ ratios, $\mathrm{O}-\mathrm{H}$ distances and partial charges of these 3-, 4- and 10-OHBaAs were similar to those of $E_{2}$ and DES (Fig. 4), suggesting that the phenol group is required to form hydrogen bonding at Glu353 of hER and to go into the active site of hER. Figure 6B shows a possible binding of 4-OHBaA to hER as an example of strongly estrogenic OHPAHs. The hydrogen bonds of 2- and 9OHBaAs to Arg394 or His524 of hER may interfere with the insertion of $E_{2}$ into the active site.

As conclusions, the following facts were obtained from the assays of estrogenic and antiestrogenic activities of fourteen PAHs and sixty-three OHPAHs in the yeast two-hybrid system. Several OHPAHs having four rings showed strongly estrogenic/antiestrogenic activities. The most strongly estrogenic and antiestrogenic OHPAHs tested were 4-OHBaA and 3-OHBcP, respectively. A rectangular plane of four rings and a phenol group were necessary for OHPAHs to bind to the site of hER and exhibit the activities. OHPAHs with stronger affinities for hER tend to have stronger activity. Activities of OHPAHs were found to depend on the three physical parameters: L/B ratio, $\mathrm{O}-\mathrm{H}$ distance and partial charge of the phenol group. These findings suggested that estrogenic OHPAHs were similar to those of $\mathrm{E}_{2}$ and DES and that the compositional flexibility of estrogenic OHPAHs was much smaller than that of antiestrogenic OHPAHs.

These facts suggest that the activities of $\mathrm{OH}-$ PAHs can be roughly predicted from their physical parameters, although differentiation of agonistic and antagonistic effects is not easy. As mentioned above, several quinoid PAHs showed strongly antiestrogenic activities. Further studies of these compounds should clarify the relationship between structures and activities of PAH derivatives.

Acknowledgements This study was supported in part by the fund from the Ministry of Environment, Japan for Scientific Research of ExTEND2005.

\section{REFERENCES}

1) Harvey, R. G. (1997) Polycyclic aromatic hydrocarbons, Wiley-VCH, New York.

2) International Agency for Research on Cancer (IARC) (2006) Monographs on the evaluation of carcinogenic risks to humans, http://monographs. iarc.fr/ENG/Classification/index.php

3) Santodonato, J. (1997) Review of the estrogenic and antiestrogenic activity of polycyclic aromatic hydrocarbons: relationship to carcinogenicity. Chemosphere, 34, 835-848.

4) Melnick, R. L. (1999) Introduction workshop on characterizing the effects of endocrine disruptors on 
human health at environmental exposure levels. Environ. Health Perspect., 107 (Suppl 4), 603-604.

5) Tran, D. Q., Ide, C. F., McLachlan, J. A. and Arnold, S. F. (1996) The antiestrogenic activity of selected polynuclear aromatic hydrocarbons in yeast expressing human estrogen receptor. Biochem. Biophys. Res. Commun., 229, 102-108.

6) Charles, G. D., Bartels, M. J., Zacharewski, T. R., Gollapudi, B. B., Freshour, N. L. and Carney, E. W. (2000) Activity of benzo[a]pyrene and its hydroxylated metabolites in an estrogen receptor $-\alpha$ receptor gene assay. Toxicol. Sci., 55, 320-326.

7) Nishihara, T., Nishikawa, J., Kanayama, T., Dakeyama, F., Saito, K., Imagawa, M., Takatori, S., Kitagawa, Y., Hori, S. and Utsumi, H. (2000) Estrogenic activities of 517 chemicals by yeast twohybrid assay. J. Health Sci., 46, 282-298.

8) Stcha, K. R., Staretz, M. E., Wang, M., Liang, L., Kenney, P. M. and Hecht, S. S. (2000) Effects of benzyl isothiocyanate and phenethyl isothiocyanate on benzo $[a]$ pyrene metabolism and DNA adduct formation in the A/J mouse. Carcinogenesis, 21, 1711-1719.

9) Kishikawa, N., Morita, S., Wada, M., Ohba, Y., Nakashima, K. and Kuroda, N. (2004) Determination of hydroxylated polycyclic aromatic hydrocarbons in airborne particulates by high-performance liquid chromatography with fluorescence detection. Anal. Sci., 20, 129-132.

10) Ebright, R. H., Wong, J. R. and Chen, L. B. (1986) Binding of 2-hydroxybenzo[a]pyrene to estrogen receptors in rat cytosol. Cancer Res., 46, 2349-2351.

11) Hirose, T., Morito, K., Kizu, R., Toriba, A., Hayakawa, K., Ogawa, S., Inoue, S., Muramatsu, M. and Masamune Y. (2001) Estrogenic/antiestrogenic activities of benzo $[a]$ pyrene monohydroxy derivatives. J. Health Sci., 47, 552-558.

12) Kamiya, M., Toriba, A., Onoda, Y., Kizu, R. and Hayakawa, K. (2005) Evaluation of estrogenic activities of hydroxylated polycyclic aromatic hydrocarbons in sigarette smoke condensate. Food Chem. Toxicol., 43, 1017-1027.

13) Morito, K., Hirose, T., Kinjo, J., Hirakawa, T., Okawa, M., Nohara, T., Ogawa, S., Muramatsu, M. and Masamune, Y. (2001) Interaction of phytoestrogen with estrogen receptor $\alpha$ and $\beta$. Biol. Pharm. Bull., 24, 351-356.

14) Collantes, E. R., Tong, W. and Walsh, W. J. (1996) Use of moment of inertia in comparative molecular field analysis to model chromatographic retention of nonpolar solutes. Anal. Chem., 68, 2038-2043.

15) Sander, L. C. and Wise, S. A. (1997) Polycyclic aromatic hydrocarbon structure index, NIST Special Publication, 922.

16) Chetiyanukornkul, T., Toriba, A., Kameda, T., Tang, N. and Hayakawa, K. (2006) Simultaneous determination of urinary hydroxylated metabolites of naphthalene, fluorine, phenanthrene, fluoranthene and pyrene as multiple biomarkers of exposure to polycyclic aromatic hydrocarbons. Anal. Bioanal. Chem., 386, 712-718.

17) Lee, H., Cho, E., Jun, J. and Ohta, A. (2007) Evaluation on antiestrogenic activities of polycyclic aromatic hydrocarbons using the yeast two-hybrid detection system for endocrine disruptors. Environ. Monit. Assess., PMID 17057947.

18) Fang, H., Tong, W., Shi, L. M., Blair, R., Perkins, R., Branham, W., Hass, B. S., Xie, Q., Diel, S. L., Moland, C. L. and Sheehan, D. M. (2001) Structureactivity relationships for a large diverse set of natural, synthetic, and environmental estrogens. Chem. Res. Toxicol., 14, 280-294.

19) Tanenbaum, D. M., Wang, Y., Williams, S. P. and Sigler, P. B. (1998) Crystallographic comparison of the estrogen and progesterone receptor's ligand binding domains. Proc. Natl. Acad. Sci. U.S.A., 95, 5998-6003.

20) Hu, J-Y., Aizawa, T. and Ookudo, S. (2002) Products of aqueous chlorination of bisphenol A and their estrogenic activity. Environ. Sci. Technol., 36, 1980-1987.

21) Tong, W., Perkins, R., Strelitz, R., Collantes, E. R., Keenan, S., Welsh, W. J., Branham, W. S. and Sheehan, D. M. (1997) Quantitative structureactivity relationships (QSARs) for estrogen binding to the estrogen receptor: Predictions across species. Environ. Health Perspect., 105, 1116-1124. 